\title{
INFORMACIÓN
}

\section{RESUMEN Y CONCLUSIONES DE LA JORNADA DE LA SOCIEDAD ESPAÑOLA DE SALUD PÚBLICA Y ADMINISTRACIÓN SANITARIA}

Santiago de Compostela, 1996.

El día 3 de octubre de 1996 se han reunido en Santiago de Compostela, Galicia, un centenar de profesionales de la salud pública con motivo de la Jornada SESPAS 1996, celebrada bajo el lema Servicios de salud pública: organización, productos y calidad.

Los participantes han revisado la situación de los servicios de salud pública en los actuales momentos de cambio del sistema sanitario. Valoran las transformaciones producidas en los últimos años, con el claro desarrollo de la salud pública como disciplina profesional y una apreciable mejora en la cualificación, dedicación y dotación de recursos humanos, que se han traducido en apreciables avances en diversos aspectos de la salud pública en España. Al mismo tiempo, constatan que tras las transferencias de competencias y recursos en salud pública a las Comunidades Autónomas desde la Administración Central, se han producido procesos de reorganización parcial de los servicios en diversas Comunidades, que han resultado en estructuras de salud pública distintas en algunos aspectos. Sin embargo, las estructuras básicas siguen basadas esencialmente en el modelo definido en 1925 y 1944.

Uno de los sectores clave para la salud pública y que debe afrontar nuevos retos derivados de los cambios en la industria y el mercado son los servicios orientados a garantizar la seguridad e higiene de los alimentos, basados en buena parte en actividades de inspección y control. Por ello, las Jornadas han dedicado buena parte de su reflexión a este sector. La Unión Europea está estimulando de forma acelerada la transformación de la industria alimentaria, y esto exige un replanteamiento de las formas en que se ha basado tradicionalmente esta actividad, incorporando a su desarrollo controles de calidad internos y externos. La gestión de los servicios de inspección cstá avanzando hacia planteamientos dirigidos a la gestión del riesgo, reorientando su trabajo hacia una dinámica con más participación de los industriales, donde el control de procesos y el control del producto final tengan su espacio, con una orientación de cooperación o asesoría y no meramente fiscalizadora. La mejora de la calidad de los servicios de salud pública en este campo se está basando en las normas europeas de calidad, apoyadas en cambios en la gestión de recursos y de personal.

Los participantes constatan que los cambios en el contexto y en los servicios asistenciales de financiación pública no han comportado un cambio paralelo en los de salud pública, aunque se han iniciado diversos procesos de reflexión valiosos que apuntan trazos nuevos. Es fundamental para el futuro de los servicios de salud pública responder a los desafíos del momento con propuestas organizativas apropiadas, y con una redefinición de su misión y sus ejes de trabajo prioritario que responda a la realidad actual.

Se valora con interés la formulación de propuestas organizativas orientadas a definir los productos y servicios de salud pública de forma explícita. La separación de las funciones de financiación y provisión de servicios actualmente en curso en nuestro Sistema Nacional de Salud presenta una oportunidad para explicitar los servicios y productos considerados necesarios para los responsables políticos. El horizonte debe tender a comprar servicios en términos de su valor añadido a la salud y no sólo en términos de producto. Asimismo, presenta una oportunidad para revisar la financiación de estos servicios y poder dotar de recursos apropiados a las actividades valoradas como prioritarias.

Se consideran como ejes fundamentales para la salud pública del futuro las actividades de análisis de las necesidades de salud, la determinación de 
políticas de salud y la garantía de prestación de servicios a la población. En un sistema sanitario que introduce elementos de competencia que han de primar la eficiencia y la producción de servicios, es aún más crucial valorar la equidad y la eficacia de los servicios, tarea propia de la salud pública. Debe tenderse a la articulación de los componentes de promoción y protección de la salud con los asistenciales, prefigurando un modelo más sensible a los problemas de salud de nuestra sociedad, de naturaleza cambiante.

Las modalidades organizativas que la salud pública adopte en este contexto pueden ser diversas, pero han de tender - como en otros sectores de la sanidad-a primar la capacidad de autoorganización de los profesionales, a introducir elementos de desarrollo e incentivación profesional, y a explicitar los recursos invertidos para obtener servicios y su coste. Fórmulas del tipo consorcio, agencia o empresa pública pueden tener interés por su agilidad de gestión, aunque ha de quedar claramente definida la función de autoridad sanitaria, con responsabilidad clara y visible y única para cada ámbito territorial y de población. Esta autoridad reside en la propia administración pública, que puede delegar o contratar la prestación de servicios. Las nuevas formas organizativas en gestión nacen con la voluntad explícita de someterse a formas de evaluación para buscar la excelencia en la praxis de la salud pública.

Santiago de Compostela, 1996 